hours or at weekends. Some such improvisation should be possible in most areas at least until finances improve and the need for centres becomes more generally accepted.

Medical staffing-Police surgeons already have responsibility for forensic examinations and in some areas are themselves organising rotas of doctors trained in the sympathetic handling of these cases. For example, in Manchester Dr Raine Roberts has arranged a rota of women police surgeons to give all women in the region a chance of being examined by a woman doctor if they request it.

Counsellors-Twenty four hour counselling cover is more difficult to achieve, and some additional funding would be needed. Three or four workers would have to be recruited and trained, although at least initially the rotas might be covered during working hours by social workers, psychologists, or nurses already working in the hospital.

Child sexual assault - The needs of child victims of sexual assault are more easily met. These children do not usually present in the dramatic fashion in the evening and at night that rape victims do. The assailants are commonly members of the family or are known to the child, and the assaults are likely to have been going on for years. ${ }^{11}$ Examination, if necessary at all, can therefore usually be arranged at more social hours, making staffing easier. An arrangement has already been made at St Mary's Hospital, Manchester, to examine child victims on a ward where forensic equipment is available, and it is hoped to arrange immediate counselling for parents and children so that they can be referred for expert help.

\section{Conclusion}

Thus sexual assault centres in some way comparable to those in Australia could and should be provided in the United Kingdom. The total number needed over the country is difficult to assess, but at least one in each major centre of population would seem essential if victims of assault are to have any hope of immediate help and longer term follow up. Sydney, with a population of $3 \cdot 28$ million, now has five centres, all fully used.

\section{References}

1 Divasto PU, Kaufman A, Rosner L, et al. The prevalence of sexually stressful events among females in the general population. Arch Sex Behav 1984;13:59-67.

2 Burgess AW, Holmstrom LL. Rape trauma syndrome. Am J Psychiatry 1974;131:981-6.

3 Gilley J. Victims of rape. Br Med $\mathcal{J} 1975$;i:453-4.

4 Nadelson CC, Notman MT, Zackson H, et al. A follow up study of rape victims. Am $\mathcal{F}$ Psychiatry 1982;139:1266-70.

5 McCrombie LS, Bassuk E, Savitz R, et al. Development of a medical center rape crisis intervention program. Am f Psychiatry 1976;133:418-21.

6 Roberts REI. The police surgeon. Joumal of the Association of Police Surgeons of Great Britain 1983; Nov (24):7-21.

7 Dellar C. The development of a sexual assault referral centre. Police Surgeon 1981:(April):90-9.

8 Connor AF. Sexual assault in south Australia: psychosociological and demographic aspects. In Proceedings of the ninth annual congress of the Australian Society for Psychosomatic Obstetrics and Gynaecology. Alice Springs: the Australian Society for Psychosomatic Obstetrics and Gynaecology, 1982:23-30.

9 Scott $\mathrm{D}$, Hewitt $\mathrm{L}$. The short term adjustment to rape and the utilisation of a sexual assault counselling service. Australian and New Zealand foumal of Criminology 1983;16:93-103.

10 Whiston SK. Counselling sexual assault victims: a loss model. The Personnel and Guidance foumal 1981 Feb:363-6.

11 Furniss T, Miller LB, Bentovim A. Therapeutic approach to sexual abuse. Arch Dis Child $1984 ; 59: 865-70$.

(Accepted 5 December 1984)

\title{
How many medicines are there?
}

\author{
ERIC S SNELL, JOHN P GRIFFIN
}

In the current debate in Britain on proposals for a national limited list of medicines for use in the National Health Service it is worth examining the effects of the national licensing system that has been in operation for many years on the "number of products" available. This number can be expressed in several different ways depending on the definition adopted for product. Products may be classed in order of increasing magnitude, as:

(1) Active ingredients (single, or in the case of combination products, multiple) regardless of their formulation into medicines.

(2) Distinctive medicines, described by brand or generic name, or both.

(3) Formulation of medicines, in specific forms and doses.

(4) Product licences, one of which must exist for each and every formulation of a medicine.

The second of these definitions would seem to be the most appropriate to represent the number of products available to a prescribing doctor or used in his private repertoire. For example, different brands of the same active ingredient-for example, Keflex and Ceporex, which are different brands of cephalexin-would be counted as two products, but duplication of these brands into formulations of tablets, capsules, and suspensions in various strengths, would not be counted separately. The third and fourth definitions describe the variants available, and each would provide similar total numbers.

The Association of the British Pharmaceutical Industry

ERIC S SNELL, MD, FRCP, director of medical and scientific affairs

JOHN P GRIFFIN, MRCP, MRCPATH, Director

Correspondence to: Dr E S Snell
At the start of product licensing in the United Kingdom in 1971 products already on the market were granted a product licence of right. A single product licence of right was allotted to every formulation of each product marketed (except for homoeopathic preparations, for which one product licence of right could cover several dilutions). The progress of the review of these old products and their status at the end of 1982 were reviewed by Penn ${ }^{1}$ in 1983 and are shown in table I.

TABLE I-Number of product licences of right in the UK

\begin{tabular}{lr}
\hline & No of licence \\
\hline Extant 1971 & 39035 \\
Lapsed, revoked, or suspended 1971-82 & 22376 \\
To be reviewed & 10322 \\
Converted to full product licences & 598 \\
\hline Total licences remaining 1982 & 10920
\end{tabular}

^The 16659 not lapsed, suspended, or revoked minus 5987 homoeopathic products and 350 other products not subject to review.

In 1982 the route of sale of these product licences of right was summarised as follows: on prescription only, 4000; from a pharmacist, 3000; and on general sale, 4000 . Since then roughly 2500 more product licences of right have been discontinued (but their breakdown by route of sale is not known), leaving a total of 8000 to 8500 historical licences.

Product licences granted for new products entering the market between 1973 and 1980 numbered $4300 .^{2}$ These comprised 204 new chemical entities for each of which several formulations required separate product licences-for example, nine for Amoxil. The remainder consisted of new formulations and presentations of 
TABLE II-Number of prescribable medicines in the UK in 1984*

\begin{tabular}{lrc}
\hline & & No \\
\hline Total active ingredients & & 1108 \\
Medicines with single active ingredients & 915 & 1507 \\
Medicines with active ingredients in combination & 592 & \\
Brand names in MIMS & & 2125 \\
Brand names in British National Formulary & & 2279 \\
\hline
\end{tabular}

^From the Monthly Index of Medical Specialities (MIMS).

TABLE III-Number of drugs listed in physicians' compendia 1981. (Reproduced from Dukes ${ }^{5}$ )

\begin{tabular}{lcccr}
\hline Country & Source & $\begin{array}{c}\text { Active } \\
\text { substances }\end{array}$ & Products & Formulations \\
\hline France & Vidal & 1000 & 2300 & 4000 \\
West Germany & Rote Liste & 2550 & 8900 & 11155 \\
Sweden & FASS & 750 & 1600 & 2500 \\
UK & MIMS & 1100 & 2100 & 3900 \\
USA & PDR & 1200 & 6000 & 12000 \\
\hline
\end{tabular}

existing entities. The breakdown of these figures by route of sale is not available.

The Department of Health and Social Security's figures for product licences and product licences of right available in 1984 totalled 15500 , of which 6000 were for homoeopathic products and 4000 for products on general sale (including such items as tooth paste), leaving 5500 to 6000 prescribable formulations. Table II shows the number of prescribable medicines available in the UK in 1984 as counted by the Centre for Medicines Research (Walker SR, personal communication). All but the first of these totals represent counts of medicines according to the second definition given above.

The figures given by the DHSS to the Informal Working Group on Effective Prescribing (Greenfield Committee) ${ }^{3}$ and presented to the Secretary of State, Mr Norman Fowler, in 1982 were as follows (para 25): "There are in the region of 6500 preparations available for prescribing at NHS expense and the new BNF lists some 4500 of these." The report continues, "In comparison, the average prescriber is said to use a range of 200-300 drugs."

Recently, government ministers have quoted figures of 17000 or 18000 as the number of medicines available in the UK under the NHS. These appear to be derived from the 1983 register developed by the Prescription Pricing Authority on the names of products appearing in FP10 scrips. ${ }^{+}$This register, however, contains over 5000 homoeopathic preparations and about 2000 items that are not medicines but are prescribable products, such as disinfectants, dressings, and appliances (trusses, elastic hosiery, urinals, etc). The remaining products in this register (about 10000 ) are duplicated if they have been prescribed under approved name and brand name, and, in addition, all formulations are listed separately (such as 18 Crystapen items).

We must conclude that the number of products on the UK market has decreased considerably over recent years, as a result of market forces and the activity of the Committee on Review of Medicines, rather than increased.

Table III shows some similar comparative data from other countries.

\section{References}

1 Penn RG. The review of medicines in the UK. Pharmacy International 1983;4;205-10.

2 Griffin JP, Diggle GE. A survey of products licensed in the United Kingdom from 1971-1981. Br 7 Clin Pharmacol 1981;12:453-63.

3 Department of Health and Social Security. Report to the Secretary of State for Social Services of the informal group on effective prescribing. London: DHSS, 1983. (Greenfield report.)

4 Statistics and Research Division of the Department of Health and Social Security. Drug master index. London: DHSS, 1983.
intics and Research Division

5 Dukes G. The effects of drug regulation. Lancaster: MTP Press, 1985

(Accepted 27 February 1985)
$\mathrm{A}$ COUPLE OF years ago the $\mathrm{BBC} 2$ series Forty Minutes was responsible for encouraging a belief in alternative remedies for cancer. Having built up its Aunt Sally, the same channel's Brass Tacks has very neatly clubbed her fairly and squarely between the eyes with its programme "The Patient's Dilemma" (27 February).

Down here in Bournemouth medicine has more fringes than a Victorian tablecloth, and one of them is the Bournemouth Centre for Complementary Medicine, which featured in the programme. It is run by an American doctor with a Mexican qualification and no licence to practise in this country. But then he doesn't need one. Under common law anyone can set himself up as a healer as long as he doesn't purport to be a registered medical practitioner. Increasing numbers are doing so. Every year, the programme told us, another $11 \%$ are purchasing their diplomas, nailing up their plates and calling themselves specialists in reflexology, applied kinesiology, radioionics, iridology, and sclerology, and for all I know analysts of ear wax. At one end of the range osteopaths, chiropracters, homoeopaths, and acupuncturists have set up a Council for Complementary and Alternative Medicine and are striving for a clean image of respectability. At the other purveyors of eastern promise paranoically see themselves as misunderstood Galileos and insist that they are paradigms - what's that?

Clearly there are some diseases where orthodox medicine has little more to offer than foot massage, but even for potentially curable conditions, like Hodgkin's disease, patients are goung to alternative practitioners.

The film gave two probably valid answers as to why they go. Firstly, there are the side effects. Effective treatment, especially for cancer, hurts. Green beer and carrot juice are harmless. Secondly, there is the desire to do something for oneself, to take responsibility for one's treatment. Chemotherapy means lying back and taking it. Thinking of England is not enough. Like a lover, the doctor must woo his patient if she is not to forsake him.-TERRY HAMBLIN, consultant haematologist, Bournemouth.

$T$ HERE IS no doubt that The Living Body (C4, Wednesdays) is beautifully produced. No expense has been spared on the wealth of computer graphics, full colour animation, and microscopic, colonoscopic, and bronchoscopic footage. The presentation is clear, the cast changes every week, and the series covers every conceivable element of human biology. So why is it so boring?

Granted it is an educational programme, but the skilful programme maker should make education look like something else. The excellent Horizon series brings us human biology in a number of guises - the voyage of discovery, the fearless investigation. Jonathan Miller expanded the subject into a grand tour of life, art, and 